\title{
Stage I Nasopharyngeal Carcinoma AJCC v8
}

National Cancer Institute

\section{Source}

National Cancer Institute. Stage I Nasopharyngeal Carcinoma A/CC v8. NCI Thesaurus.

Code C132817.

Stage I includes: T1, N0, M0. T1: Tumor confined to the nasopharynx, or tumor extending to oropharynx and/or nasal cavity without parapharyng eal involvement. N0: No regional lymph node metastasis. M0: No distant metastasis. (AJCC 8th ed.) 